\title{
A MORALIDADE ADMINISTRATIVA E A NOVA LEI DO TRIBUNAL DE CONTAS DA UNIÃO
}

Episódios recentes da história política nacional colocam no centro dos debates o princípio da moralidade administrativa e a conduta dos gestores da coisa pública. Especialmente são avaliados os procedimentos legais de contenção e repressão da conduta ilícita dos administradores públicos.

O procedimento do impeachment do Presidente da República sai da literalidade do texto constitucional e das páginas da doutrina jurídica para a inédita experiência do processo perante o Senado e o Supremo Tribunal Federal.

A luta fratricida se converteu em questão nacional, convocou as ruas e os lares na mobilização do sentimento cívico e na participação popular, expressa formalmente na iniciativa de representativas instituições de classe.

A corrupção se tornou tema presente na repulsa a inaceitáveis desvios de conduta de homens públicos. A: tolerância com práticas notórias (rouba, mas faz) cedeu lugar à inconformidade com desuses de ética e a rendosa prática da intermediação nos investimentos públicos.

Certamente, a corrupção tem raízes seculares na história dos costumes políticos, aqui e alhures. De logo acodem à lembrança os sermões de Vieira sobre à conjugação do verbo rapio e o modelar tratado sobre a Arte de Furtar com que o autor anônimo diagnosticou objetivamente os hábitos da burocracia colonial.

Em verdade, o desvio ético coincide com à história da humanidade. $O$ primeiro ato de corrupção pode ser imputado à serpente seduzindo Adão com a oferta da maçã, na troca simbólica do paraíso pelos prazeres ainda inéditos da carne. A decadência de Roma Imperial foi estimulada pela corrupção dos costumes, inclusive na vida política.

Manoel Figueiredo Ferraz, em artigo publicado na Revista de Direito Administrativo (volume 72/37), documentou a corrupção eleitoral no Império Romano, no qual a severidade das leis proibitivas (as chamadas leis de ambitu) não impediu a permanência da compra de votos e a manipulação da publicidade em benefício dos candidatos. 
O auxílio à fuga de escravos, ou a corrupção destes estimulada por terceiros, era objeto, em Roma, de especial ação de reparação (actio servo corruptio), obrigando o autor a indenizar o proprietário do escravo pelo dobro do dano causado.

Nas ditaduras asiáticas e latino-americanas a limitação das liberdades políticas se associou aos negócios escusos, propiciadores de respeitáveis fortunas que alimentam contas bancárias secretas.

Na prática norte-americana a corrupção no serviço público tem sido documentada na literatura política e jurídica.

São conhecidos os escândalos que marcam a administração do Presidente Grant, desde a chamada quadrilha do uísque, com a sonegação de impostos e as concessões lucrativas para explorar o comércio, que levaram ao processo de Impeachment do Ministro da Guerra William Belknap. A administração do Presidente Harding ficou marcada pelo escândalo de arrendamento das reservas de óleo do Teapot Dome, que se tornou o símbolo da corrupção, levando à morte o Presidente pela exaustão psicológica.

$\mathrm{Na}$ era Truman foram anotados casos de corrupção que inspiraram inquéritos parlamentares e no Governo Eisenhower elementos de sua administração foram levados à renúncia pela conduta imprópria em negócios públicos.

A corrupção na Municipalidade de Nova York foi especialmente examinada em recente artigo publicado na revista Urban Affairs Quartely - junho de 1992. Estudo sobre o noticiário de inspeções administrativas de 1940 a 1980 evidencia 14 casos de corrupção, ou seja, a média de um escândalo a cada dois anos e meio. As várias leis municipais que ali visam garantir a ética na administração e a coibir os abusos de poder das autoridades não são a rigor executadas, segundo os depoimentos dos autores, que aconselham a criação de uma promotoria especial para o combate à corrupção no governo.

Alguns episódios ilustram a história da corrupção na cidade de Nova York.

O Prefeito O'Dwyer (1946-1950), foi levado a renunciar pela prática de corrupção eleitoral.

$\mathrm{Na}$ administração do Prefeito JOHN LINDSAY as acusações de corrupção em obras públicas levaram à condenação criminal do responsável pelo abastecimento de água.

Informam os autores que, desde 1940, nenhuma administração municipal escapou à pecha de corrupção, culminando com os escândalos da administração do Prefeito Edward Kock (1978-1980).

Mais expressiva é a tolerância com a conduta ilícita de funcionários que solicitam vantagens para o cumprimento de deveres de ofício, qualificada como honest graft (suborno honesto), algo que poderá corresponder na gíria .ıacional, ao tolerado hábito de vender facilidades, ou, em imagem gastronômica, a comer bola para digerir pretensões das partes. Aquilo que, na gíria de língua espanhola, é a mordida, na prática italiana a bustarella (a luva), ou, na terminologia indiana, speed money (dinheiro rápido).

Nixon foi levado à renúncia, na iminência de ser afastado do poder em processo de impeachment, em face de comprovados abusos de poder, entre os quais a mal explicada origem de recursos na reforma de sua casa de campo. 
O mundo comercial é, por natureza, o grande palco de fraudes e negócios escusos, na medida em que o risco e o lucro são as duas alavancas em que se inspira a alma do comércio. Em Roma, Mercúrio era, ao mesmo tempo, o Deus dos comerciantes e dos ladrões.

A história das sociedades mercantis está semeada de escândalos financeiros, de tal modo que, expressões de Ibering, os Conselhos de Administração das S.A. abrigam mais crimes e criminosos que as penitenciárias.

Quem não se lembra, entre nós, do encilhamento, ao início da República, e, mais moderadamente, das filipetas, do "boom" manipulado das bolsas de 1970 e do caso recente atribuído a Nagi Nahas?

Poder e lucro são o estímulo da corrupção nos negócios financeiros e nas fraudes tributárias em que se erırelaçam fiscais e fiscalizados.

A lei combate a concorrência desleal e os abusos de poder econômico, documentados nos inquéritos do Banco Central e da Comissão de Valores Mobiliários.

No campo eleitoral, a compra de votos, em troca de favores, servia de base ao poder político dos coronéis, a que Victor Nunes Leal dedicou um livro modelar e clássico sobre "Coronelismo, enxada e voto". As nomeações abundantes de correligionários, antes ou depois das eleições, caracterizavam os testamentos políticos, repudiados na jurisprudência do Supremo Tribunal Federal na década de 60 (Revista de Direito Administrativo, vol. 59/338). E a força da publicidade ilícita, que permite a criação de mitos e a falsidade de denúncias escandalosas está a reclamar um estudo profundo sobre as deformações do processo eleitoral e a participação da midia.

No âmbito da Administração Pública, a corrupção é definida como a conduta ilícita do servidor que aceita ou solicita vantagens para a prática de ato de ofício. Assim se identifica a figura penal da comoção passiva.

A hipótese é, por natureza, a de um crime bilateral que supõe a ação de outro agente, externo à Administração, que, pela oferta ou promessa de vantagem, igualmente ingressa no campo penal, como autor do crime de corrupção ativa. São dois delitos de concurso necessário, ambos autônomos, que, no entanto, reciprocamente se condicionam. A ação de quem recebe corresponde a ação de quem dá ou oferece. Tanto a corrupção ativa como a passiva se distinguem como própria ou imprópria. A primeira supõe a violação de um dever funcional. Na segunda, embora lícito o fato de ofício, a percepção de vantagem tipifica o crime. $O$ bem jurídico protegido tanto a regularidade do serviço como a moralidade administrativa. A coação do funcionário sobre o administrado ou o contribuinte, extorquindo-lhe vantagem ilícita, formaliza o crime de concussão (expressão cujo étimo concutere representa o ato de sacudir a árvore para extrair-lhe os frutos). A tolerância com os faltosos ou omissos identifica o crime de condescendência criminosa. Igualmente o exercício irregula: da função pública para alcançar interesse pessoal tipifica o crime de prevaricação. A seu turno, a interferência, do funcionário em matéria estranha à sua competência para favorecer as partes interessadas define o crime de advocacia administrativa.

O combate à corrupção conduz à responsabilidade penal (crimes funcionais acima descritos), assim como à responsabilidade administrativa e, subsidiariamente, à responsabilidade civil do funcionário público. 
Na instância judiciária, a par dos processos criminais, a ação popular e a ação civil pública facultam a iniciativa popular, ou do Ministério Público, como Instrumento de controle da legalidade nos atos da Administração Pública e se especializam combate à corrupção e a seus efeitos danosos ao patrimônio público.

A Constituição republicana de 1891 firmou o princípio da responsabilidade dos funcionários públicos pelos abusos e omissões em que incorressem ao exercício dos cargos, assim como pela indulgência ou negligência em não responsabilizarem seus subordinados. Igual preceito se repete nas Constituições seguintes. A Carta de 1946 aditou outra norma visando a reprimir o enriquecimento ilícito na função pública com as sanções de sequiestro e perdimento de bens. A partir de 1957 foi a matéria lutada em lei ordinária: primeiramente a Lei $n^{\circ} 3.164$, de $1^{\circ}$ de junho de 1957 , sucedida pela Lei $\mathrm{n}^{\circ} 3.502$, de 21 de dezembro de 1958 . Ambas foram substituídas pela recente Lei $\mathrm{n}^{\circ} 8.459$, de 2 de junho de 1992 que regula o procedimento administrativo e judicial em casos de improbidade no exercício de mandato, cargo, emprego ou função na administração direta, indireta ou fundacional. São definidos os casos de improbidade que importem enriquecimento ilícito ou causem prejuízo ao erário, facultada a qualquer pessoa a iniciativa de representação. À atual Constituição, mais severa, sanciona a prática de atos de improbidade com a suspensão de direitos político, a perda da função pública, a indisponibilidade dos bens e a obrigação de ressarcir ao erário, sem prejuízo da ação penal cabível (art. $37, \S 4^{\circ}$ ).

Mais construtiva, porém, do que a sanção de desvios de conduta funcional será a adoção de meios preventivos que resguardem a coisa pública de manipulações dolosas ou culposas. Mais valerá a contenção que a repressão de procedimentos ofensivos moralidade administrativa. Os impedimentos legais à conduta dos funcionários públicos e as incompatibilidades de parlamentares servem de antídoto às facilidades marginais que permitem a captação de vantagens ilícitas. A lei - e já agora a Constituição - obriga a prévia licitação para o compromisso de despesas e submetem a controle os contratos administrativos, assim como a distribuição de publicidade oficial. A obrigatoriedade de concursos públicos favorece a seleção pelo mérito no acesso aos cargos públicos. A atual Constituição estimula, ainda, a participação popular no controle da legalidade e da legitimidade dos atos da Administração Pública. A ação popular, como a ação civil pública, são instrumentos adequados ao combate de ilicitudes e malversações mediante a contenção de abusos do poder administrativo.

Entre os meios preventivos, em garantia da boa gestão orçamentária, avança historicamente a criação do Tribunal de Contas, como fiscal da exação nas obrigações financeiras assumidas pelo Poder Público.

Ainda no Império, Manoel Alves Branco propunha, em 1845, a criação de um Tribunal de Contas, inspirado no modelo europeu. O projeto de lei não prosperou e, conforme o diagnóstico de Rui Barbosa, "dormiu o bom sono de que raramente acordam as idéias úteis" (Comentário à Constituiçâao Federal, vol. 6, pág. 431).

Com o advento da República e pela iniciativa de Rui, então Ministro da Fazenda, nasceu o Tribunal de Contas, ainda na fase do Governo Provisório e a novidade foi incorporada à Constituído de 1891 , cujo art. 89 autorizou a instituição de "um tribunal de contas para liquidar as contas da receita e despesa e verificar a sua legalidade, antes de serem prestadas ao Congresso". 
Rui definiu em palavras, que se tornaram clássicas, a finalidade da instituição:

"Convém levantar entre o poder que autoriza periodicamente a despesa e o poder que cotidianamente a executa, um mediador independente, auxiliar de um e de outro, que comunicando com a legislatura e intervindo na administração, seja não só o vigia como a mão forte da primeira sobre a segunda, obstando a perpetuado das infrações orçamentarias por um veto oportuno aos atos do Executivo que, direta ou indireta, próximo ou remotamente, discrepem da linha rigorosa das leis de finanças."

As sucessivas Constituições da República conservaram e ampliaram a presença do Tribunal de Contas na competência de controle da despesa pública.

A Constituição de 1934 confere-lhe à missão de acompanhar a execução orçamentária e de julgar as contas dos responsáveis por dinheiros ou bens públicos (art. 99). impondo o prévio registro de contratos que, por qualquer modo, interessarem à receita ou a despesas, como requisito de serem tidos por perfeitos e acabados, como em geral, qualquer ato administrativo de que resultasse obrigações de pagamento pelo Tesouro Nacional, ou à sua conta. A recusa de registro teria caráter proibitivo, salvo autorização especial do Presidente da República sujeita a revisão pela Câmara de Deputados (art. 101 e $\$ \S 1^{\circ}$ e $2^{\circ}$ ).

A Constituição de 1937, em seu art. 114, manteve a competência do Tribunal de Contas, que a Constituição de 1940 ratificou (art. 77).

Igualmente incumbe ao Tribunal de Contas, em sua competência constitucional, emitir parecer prévio sobre as contas anuais do Presidente da Kepública, a serem julgadas pelo Poder Legislativo.

A Constituição de 1967, emendada em 1969, conserva o papel de relevo do Tribunal de Contas no processo de fiscalização financeira e orçamentária, como órgão auxiliar do Congresso Nacional, no controle externo das finança públicas (art. 71).

Caracterize-se a distinção entre o controle externo, por essa forma exercido pelo Legislativo e os sistemas de controle interno do próprio Poder Executivo (art. 72).

Em toda essa longa existência, o Tribunal de Contas, com variações em sua funcionalidade, tornou-se o centro de controle da gestão financeira orçamentária, progressivamente dilatada para alcançar primeiramente, às autarquias e a seguir todo o conjunto das empresas estatais.

A diligente atuação do Tribunal de Contas se defrontava, porém, com dois óbices históricos. De uma parte, sua atividade de controle se exercia, dominantemente, no tocante a atos consumados ou em curso de execução e, de outra parte, se concentrava no exame formal dos atos e contratos submetidos a registro ou controle. No depoimento autorizado de Luiz Octávio Gallotti que então integrava o Tribunal de Contas (e atualmente ocupa o alto cargo de Ministro do Supremo Tribunal Federal) as novas responsabilidades oriundas do modelo constitucional de 1967 e do Decreto-Lei $n^{\circ}$ 199, de 1967, revigoraram a presença do Tribunal de Contas antes "acomodado, numa atitude passiva que se nutria sobretudo na apreciação prévia das despesas, cujo alcance vinha diminuindo progressivamente. Já que sucessivas leis haviam relatado muitos casos para exame posterior" ("O Tribunal de Contas da União e a prática de sua competência constitucional - in Revista de Direito Administrativo - volume 131 - janeiro-março de 1978). 
As tomadas de contas até então "instruídas e julgadas com base em método estático, praticamente restrito a verificação dos documentos que fossem entregues ao Tribunal" se revitalizaram com a implantado do sistema de auditoria financeira e orçamentária sobre as unidades administrativas dos Três Poderes, com apoio nos sistemas de controle interno da própria Administração.

$O$ alcance do controle do Tribunal de Contas dilatou-se, sensivelmente, na medida em que passou a alcançar as múltiplas empresas estatais, assim como o acompanhamento da aplicação dos Fundos de Participação dos Estados e Municípios.

A este quadro da posição do Tribunal de Contas a Constituição em 1988 trouxe nova fisionomia dinamizando a presença tradicional do órgão de controle.

A fiscalização adquire campo mais amplo. Mais do que apenas financeira e orçamentária alcança igualmente feição contábil, operacional e patrimonial, compreendendo todas as entidades da administração direta e indireta, inclusive fundações e sociedades instituídas e mantidas pelo Poder Público.

E, mais ainda, o controle a ser exercido pelo Congresso Nacional, com o auxílio do Tribunal de Contas, vai além da legalidade. Dirige-se também à legitimidade e economicidade na gestão financeira, dilatando-se ao exame da aplicação de subvenções e aos casos de renúncia de receitas, ou seja, aos favores de incentivos fiscais (art.70).

Torna-se universal a obrigação de prestar contas extensivas a toda e qualquer pessoa física ou jurídica que utilize, arrecade, guarde, gerencie ou administre dinheiros, bens e valores públicos ou pelos quais a União responda bem como aquele que, em nome desta, assuma obrigações de natureza pecuniária.

Ao Tribunal de Contas incumbe, primariamente, participar do sistema de controle externo assim discriminado, cumprindo-lhe, a par da emissão de parecer prévio sobre as contas anuais do Presidente da República, julgar as contas dos responsáveis por dinheiros, bens e valores públicos, especialmente quando importem prejuízo ao erário.

Inovadoramente, incluiu-se na competência do Tribunal de Contas o exame de legalidade de atos de admissão de pessoal, a qualquer título, a fiscalização das contas nacionais de empresas supranacionais e de quaisquer recursos repassados pela União aos Estados, Distrito Federal e Municípios.

Na ação dinâmica que lhe é deferida, o Tribunal de Contas realizará inspeções e auditorias em unidades administrativas de qualquer dos Três Poderes e nas entidades descentralizadas.

Para alcançar tão extenso campo de ação todo um elenco de medidas disciplinares lhe são afetos na nova Constituição.

Não somente aplicará aos responsáveis por ato ilícito ou irregularidade nas contas, as sanções previstas em lei. inclusive multa proporcional à gravidade do dano causado.

Em caso de apuração de ilegalidade poderá determinar prazo para que o autor venha sanear o ato impugnado e, se não atendido, caber-lhe-á sustar a execução, comunicando a decisão à Câmara de Deputados e ao Senado Federal.

Em caso de contrato, o ato de sustado será adotado diretamente pelo Congresso Nacional, que solicitará ao Poder Executivo a adequada correção. Na anterior Cons- 
tituição, o silêncio do Congresso Nacional em 30 dias, tornava insubsistente a impugnado do Tribunal de Contas.

Agora a situação se inverte. Omissos o Congresso Nacional, ou o Executivo, o Tribunal de Contas reassumirá competência plena para decidir sobre a matéria, prevalecendo portanto, sua deliberação final.

As decisões do Tribunal de Contas de que resulte imputação de débito ou aplicação de multa terá eficácia de título executivo, constituindo dívida líquida e certa sujeita a cobrança judicial.

A composição do Tribunal de Contas encontra, na Constituição de 1988, novo modelo de provimento dos nove cargos de Ministro, que o integram.

Um terço de seus membros será escolhido pelo Presidente da República, com aprovação do Senado Federal, sendo dois, alternadamente, recrutados dentre auditores e membros do Ministério Público, indicados em lista tríplice pelo próprio Tribunal.

Os dois terços restantes são de escolha direta do Congresso Nacional, respeitados, em ambos os casos, os requisitos legais exigidos pua o provimento dos cargos.

A par do controle externo, afeto ao Congresso Nacional, a Constituição impõe a cada qual dos Três Poderes a manutenção de sistemas de controle interno, destinados a avaliar o cumprimento de metas e programas de governo, a legalidade dos atos e a avaliação dos resultados, quanto à eficácia e eficiência da gestão.

Qualquer cidadão, partido político, associação ou sindicato é parte legítima para denunciar irregularidades ou ilegalidades perante o Tribunal de Contas da União.

Finalmente, todo o sistema estipulado para a União deverá encontrar símile nos Tribunais de Contas dos Estados e no Distrito Federal.

A Constituição veda a criação de tribunais, Conselhos ou órgãos de Contas Municipais (art. $31, \S 4^{\circ}$ ), ressalvada a permanência dos existentes. A exceção, todavia, como lembra Manoel Gonçalves Ferreira Filho, tão-somente favorece o Município de São Paulo, único tribunal sobrevivente à extinção geral determinada na vigência da Constituição anterior (Emenda Constitucional n 1/69, art. 191).

Transfigurou-se, portanto, a partir da nova Constituição, o porte de competência do Tribunal de Contas, tanto pela ampliação de seus poderes e prerrogativas, como pelo fortalecimento da ação preventiva a ele conferida.

Somou-se ao controle de legalidade a figura do controle operacional e de economicidade, a importar um exame qualitativo do mérito da gestão, de especial relevo quanto a órgãos da administrado descentralizada, em suas variadas modalidades.

O acompanhamento da receita e da despesa vai além de sua abrangência direta para alcançar tanto os casos de redução, pela via dos benefícios fiscais, como as novações resultantes da transferência de receita a outras pessoas jurídicas de direito público.

Era mister que o novo esquema constitucional viesse a se refletir na reforma da legislação própria do Tribunal de Contas.

Neste sentido, após três anos de tramitado, a recente Lei $n^{\circ} 8.443$, de 16 de julho do corrente ano, em sintonia com as diretrizes constitucionais, atende às competências ampliadas e reforçadas do Tribunal e faculta adequada fiscalização operacional do serviço público da União. 
Um novo desafio se coloca para uma efetiva e real supervisão dos negócios financeiros da União, em seus diversos quadrantes, articulando-se o controle externo com os mecanismos do controle interno afeto às próprias unidades administrativas.

Ao Tribunal de Contas é reconhecido o poder regulamentar que o habilita a expedir atos e instruções normativas.

Três são as modalidades de decisão admitidas em processo de toma ou prestação de contas; preliminar, definitiva ou terminativa. A primeira, de iniciativa do Relator ou do plenário, tem caráter preparatório; a segunda importa julgamento de mérito, declarando-se as contas regulares, regulares com ressalva ou irregulares.

Por último, será terminativa quando, em razão de caso fortuito ou força maior, comprovadamente alheio à vontade do responsável, as contas forem consideradas iliquidáveis.

Dispõe a lei, em minúcias, sobre o processo de apreciação das contas e de fiscalização, assim como sobre o exame dos atos sujeitos a registro.

É no âmbito dos contratos que se torna relevante a presença do Tribunal de Contas, a partir do controle das licitações que a eles devem preceder. A jurisprudência consolida, a esse título, a eficiência do processo seletivo garantindo igualdade entre os licitantes e a imparcialidade no julgamento em favor da melhor proposta.

Nesse particular, merece referir que, em trâmite adiantado no Senado Federal, cuida-se de aperfeiçoar a lei federal sobre licitações e contratos administrativos, cujos princípios e normas gerais se aplicará em âmbito estadual e municipal.

Dois aspectos inovadores devem ser destacados na nova lei, aos quais o Regimento Interno do Tribunal, em fase de elaboração, oferecerá contornos definitivos.

O art. 44 - introduzido no Senado Federal, em substitutivo da lavra do Senador Pedro Simon - confere ao Tribunal, de ofício ou a requerimento do Ministério Público, determinar a medida cautelar de afastamento temporário do responsável, se houver indícios suficientes de sua possível interferência na regularidade de auditoria ou inspeção em curso. De igual modo, caberá, na hipótese, a indisponibilidade de bens do responsável, por prazo não superior a um ano, como garantia do ressarcimento dos danos em apuração.

Ademais das sanções ordinárias de multa ou de cobrança executiva de débito, o Tribunal está habilitado a determinar medidas extraordinárias em função de irregularidades comprovadas.

Se o Tribunal, por maioria absoluta de seus membros, considerar grave a infração cometida, poderá declarar a inabilitado coo responsável para o exercício de cargo em comissão ou função de confiança, por prazo entre cinco e oito anos.

E, ainda, poderá solicitar à Advocacia Geral da União ou aos dirigentes das entidades fiscalizadas, as medidas necessárias ao arresto de bens dos responsáveis julgados em débito, somente passíveis de liberação, com sua anuência.

$\mathrm{Na}$ moldura na nova Constituição, a lei que a regulamenta fortalece o Tribunal de Contas na altitude de seu novo papel de pleno defensor da regular gestão dos dinheiros e bens públicos e, sobretudo, na moralidade administrativa.

Dotado de novas competências e de meios renovados de ação fiscalizadora, o Tribunal de Contas da União é chamado à função eminente de fiador da repressão e 
contenção de condutas ilícitas que, a qualquer título, ofendam a boa gestão da coisa pública.

Sua intransigente defesa da legalidade se opõe aos interesses espúrios de sobrefaturamentos e outras formas de corrupção administrativas.

O modelo traçado ao Tribunal de Contas da União deverá transmitir-se as equivalentes instituições estaduais, convocadas a exercer papel idêntico na garantia dos valores éticos na aplicação de recursos do erário, zelando pela integridade do patrimônio coletivo. 


\section{Contrato com Pessoa a Declarar}

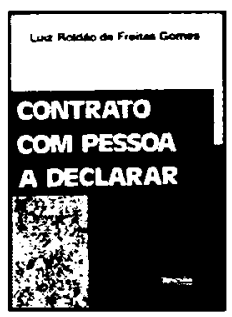

Luiz Roldão de Freitas Gomes

Ref. 0073

Brochura

300 págs.

Form. $14 \times 21$

1994

ISBN 85-7147-215-7

Como prefacia o Protessor Caio Mário da Silva Pereira, esta brilhante obra enfrenta com segurança o grande problema da natureza juridica do contrato com pessoa a declarar, apresentando as linhas fundamentais deste polêmico contrato, distinguindo-o de figuras afins, traçando-lhe os contornos históricos e comparativos e estudando os seus requisitos, a sua natureza, suas formas e modalidades e os seus efeitos.

\section{Conversão Substancial do Negócio Juridico}

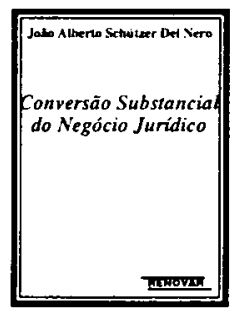
Joāo Alberto Schützer Del Nero

Ref. 0299

Brochura

480 págs.

Form. $13,5 \times 21$

2000

ISBN 85-7147-237-8

Esta obra, ao tratar da conversão - instituto posto a meio caminho entre as exigências formais do Direito e as exigências substanciais da Justiça -, preenche uma lacuna na literatura juridica nacional. 0 autor examina os antecedentes históricos da conversão, estendendo-se, em seguida, sobre o direito alemão, desembocando em rigorosa conclusão dogmática. 0 leitor encontrará, na obra, método estrito, linguagem escorreita, teoria elaborada e aplicação prática.

\section{Curso de Direito Civil - Direito das Sucessões}

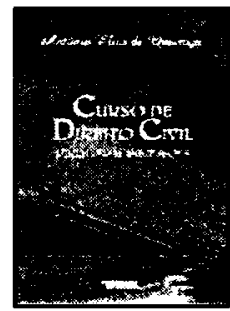

Antônio Elias de Queiroga

Ref. 0531

Brochura

296 págs.

Form. $14 \times 21$

2005

ISBN 85-7147-467-2
Todas as matérias que compōem esse vasto ramo do Direito foram cuidadosamente examinadas. 0 autor procurou dar resposta às diversas questões controvertidas que o legislador nos legou com o Código Civil de 2002. Caberá aos tribunais, como intérpretes derradeiros das leis, decidir sobre o acerto ou não das posições adotadas. Este livro, a exemplo dos anteriores lançados pelo autor, é um compêndio voltado para a didática e a praticidade.

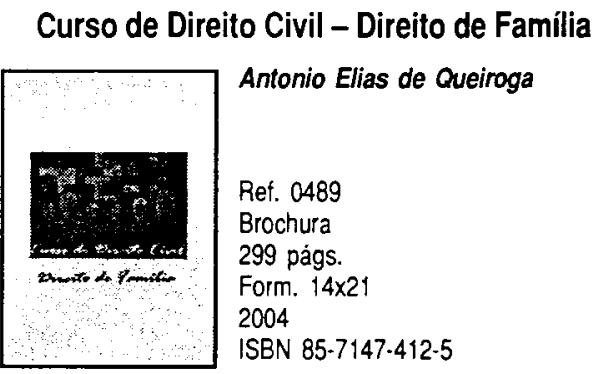

Como revela a obra, o novo Código Civil traz várias alterações no Direito de Família, que o autor aponta com precisão, buscando interpretá-las com a acuidade que the é peculiar. 0 novo Código Civil, no Livro do Direito de Familia, privilegia a dignidade da pessoa humana, havida como cláusula geral de tutela da personalidade e fundamento da República Federativa do Brasil no artigo 1 . inciso Ill da Lei Maior. 